\title{
With Asymmetric Hydrogenation Towards a New, Enantioselective Synthesis of Orlistat
}

\author{
Rolf Birk ${ }^{b}$, Martin Karpf ${ }^{a}$, Kurt Püntener ${ }^{\star a}$, Michelangelo Scalone ${ }^{\mathrm{a}}$, Mark Schwindt ${ }^{\mathrm{c}}$, and \\ Ulrich Zutter ${ }^{\mathrm{a}}$
}

\begin{abstract}
A new, enantioselective synthesis of Orlistat suitable for large-scale production is described, wherein the first enantiomerically pure intermediate methyl $(R)$-3-hydroxy-tetradecanoate is prepared via asymmetric hydrogenation of methyl 3-oxotetradecanoate. The relevant criteria associated with the application of the asymmetric hydrogenation technology are addressed, such as the activity, the selectivity and the availability of the catalyst as well as the quality of the hydrogenation substrate and the hydrogen gas.
\end{abstract}

Keywords: Asymmetric hydrogenation · Gastrointestinal lipase inhibitor · $\beta$-Ketoester · Process research

\section{Introduction}

Orlistat (1), the active pharmaceutical ingredient of Xenical ${ }^{\mathrm{TM}}$, is a novel anti-obesity agent that selectively inhibits gastrointestinal lipases, reducing the absorption of dietary fat by about $30 \%$ (Fig. 1) [1]. Also known as (-)-tetrahydrolipstatin or N-formyl- $(S)$-leucine $(S)-1-[(2 S, 3 S)$-3-hexyl-4oxo-2-oxetanyl]methyl-dodecyl ester, $\mathbf{1}$ is the hydrogenated derivative of lipstatin, a naturally occurring lipase inhibitor isolated from Streptomyces toxytricini [2]. (-)-Tetrahydrolipstatin has been the research target of numerous synthetic groups [3].

\footnotetext{
${ }^{*}$ Correspondence: Dr. K. Püntenera

Tel.: + 41616889374

Fax: + 41616881670

E-Mail: kurt.puentener@roche.com

F. Hoffmann-La Roche Ltd

Pharmaceuticals Division

aSafety and Technical Sciences

Synthesis \& Process Research

bPharma Technical Development Actives Basel

Grenzacherstrasse 124

$\mathrm{CH}-4070$ Basel

${ }^{\mathrm{R}}$ oche Colorado Corporation

Boulder Technology Center

2075 North 55th Street

Boulder, Colorado 80301, USA
}

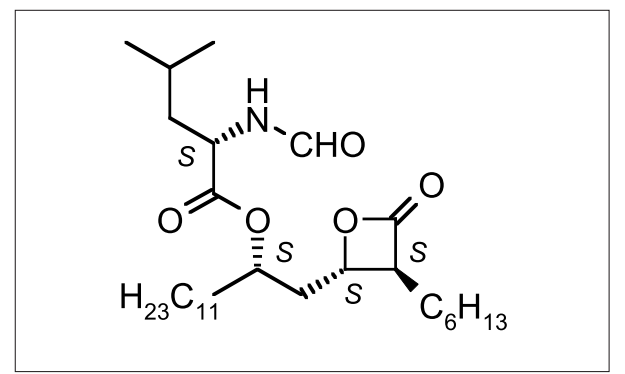

Fig. 1. Orlistat (1)

A diagram of the first-generation Orlistat synthesis based on the optical resolution of the racemic key intermediate 4 is shown in Scheme 1 [3u]. The isolated intermediates are the racemic dihydropyranone 2 , racemic all-cis $\delta$-lactone 3 , the enantiomerically-pure 1:1 PEA-salt $\mathbf{4}$, and the $(S, S, R)$-oxetanone 5 (HBL).

The required relative configuration of the three stereocenters in $\mathbf{3}$ was established during the diastereoselective, heterogeneous hydrogenation of $\mathbf{2}$, which afforded 3 as a 1:1 mixture of the two all-cis enantiomers. Subsequently, the required absolute configuration for each of these centers was selected by the optical resolution of 4 . Finally, the fourth chiral center of Orlistat was introduced during the coupling reaction of 5 with $\mathrm{N}$-formyl-( $S)$-leucine.

The objective to elaborate a new, enantioselective, second-generation synthesis of 1 was to demonstrate and to develop a more efficient process with an increased throughput. The strategy therefore was to retain the final reaction sequence $\mathbf{4}$ to $\mathbf{1}$ but to avoid the first-generation's late-stage op- tical resolution of $\mathbf{4}$ by the use of enantiomerically pure intermediate $\mathbf{1 2}$ rather than its racemate 2 .

From the several, preliminarily evaluated synthetic routes [4] to $\mathbf{1 2}$, the magnesium-mediated route [5] was finally selected because of its superior technical potential (Scheme 2).

As a first key step an asymmetric hydrogenation of methyl 3-oxotetradecanoate 6 is involved. Several methods to synthesize 9 had been described in the literature or elaborated in-house prior to the start of our investigations, i.e.:

a) Baker's yeast reduction of the potassium salt of 3-oxotetradecanoic acid (>98\% ee, $40 \%$ yield) and subsequent esterification [6];

b) Lipase-catalyzed transesterification of racemic 9 (70\% ee, $46 \%$ yield) [7];

c) Raney-nickel/tartaric acid catalyzed asymmetric hydrogenation of $\mathbf{6}$ (84$91 \%$ ee, $80 \%$ yield and $>99 \%$ ee after crystallization) [8] and

d) Ruthenium-catalyzed asymmetric hydrogenation applying a $(S)$-BINAP [9] or a $(S)$-BIPHEMP [10] based catalyst ( $97 \%$ ee, $95 \%$ yield and $>99 \%$ ee after crystallization).

The baker's yeast reduction and the lipase-catalyzed transesterification approach were considered to be unsuitable for a technical process due to their moderate yields of less than $50 \%$. In contrast, the Raneynickel/tartaric acid catalyzed asymmetric hydrogenation was successfully used in the first in-house production of $9(2 \mathrm{t}, 160$ $\mathrm{kg}$ batch scale). On small scale (6 kg), the catalyst could be recycled up to 15 times, 


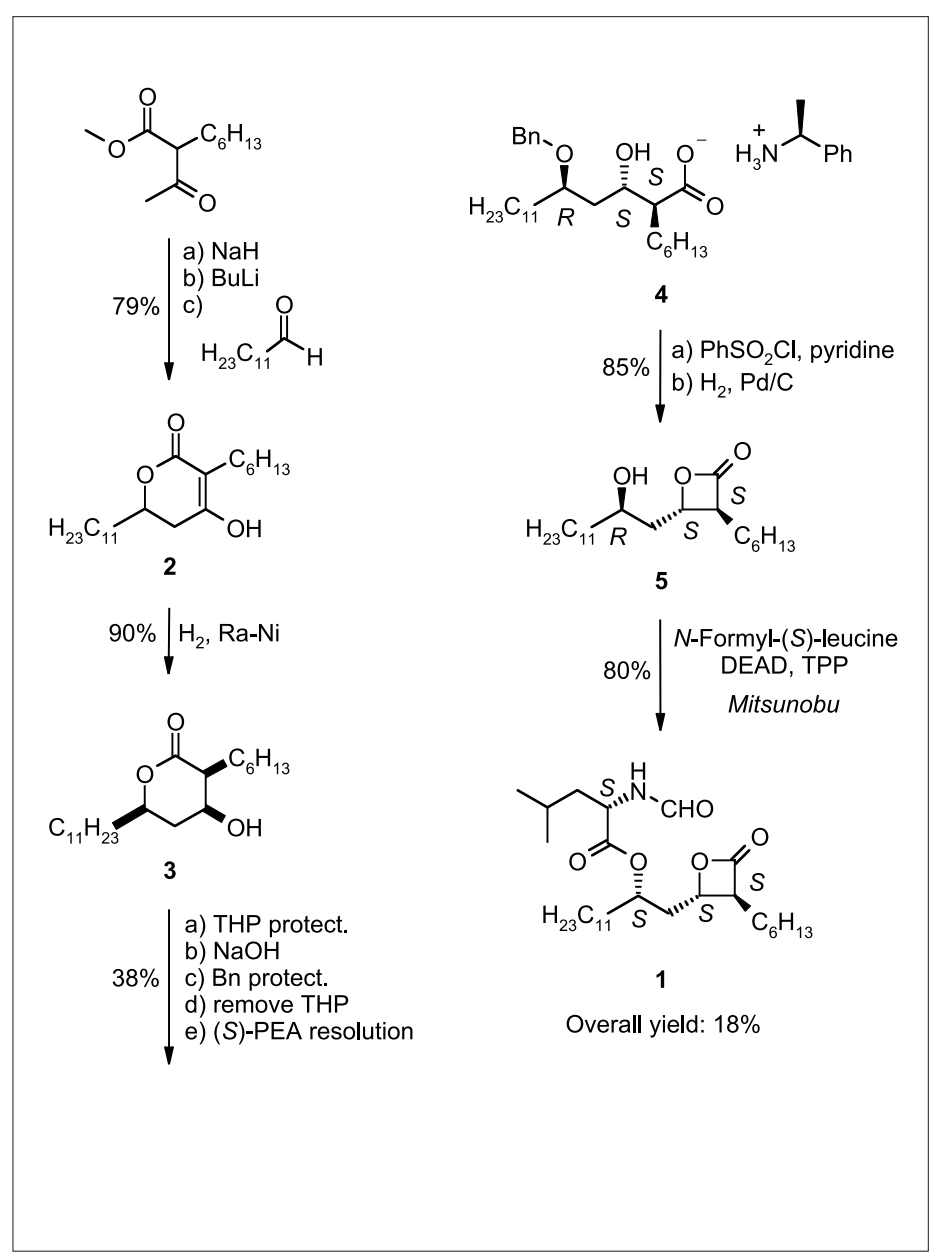

Scheme 1. First-generation, optical resolution based synthesis of Orlistat (1)

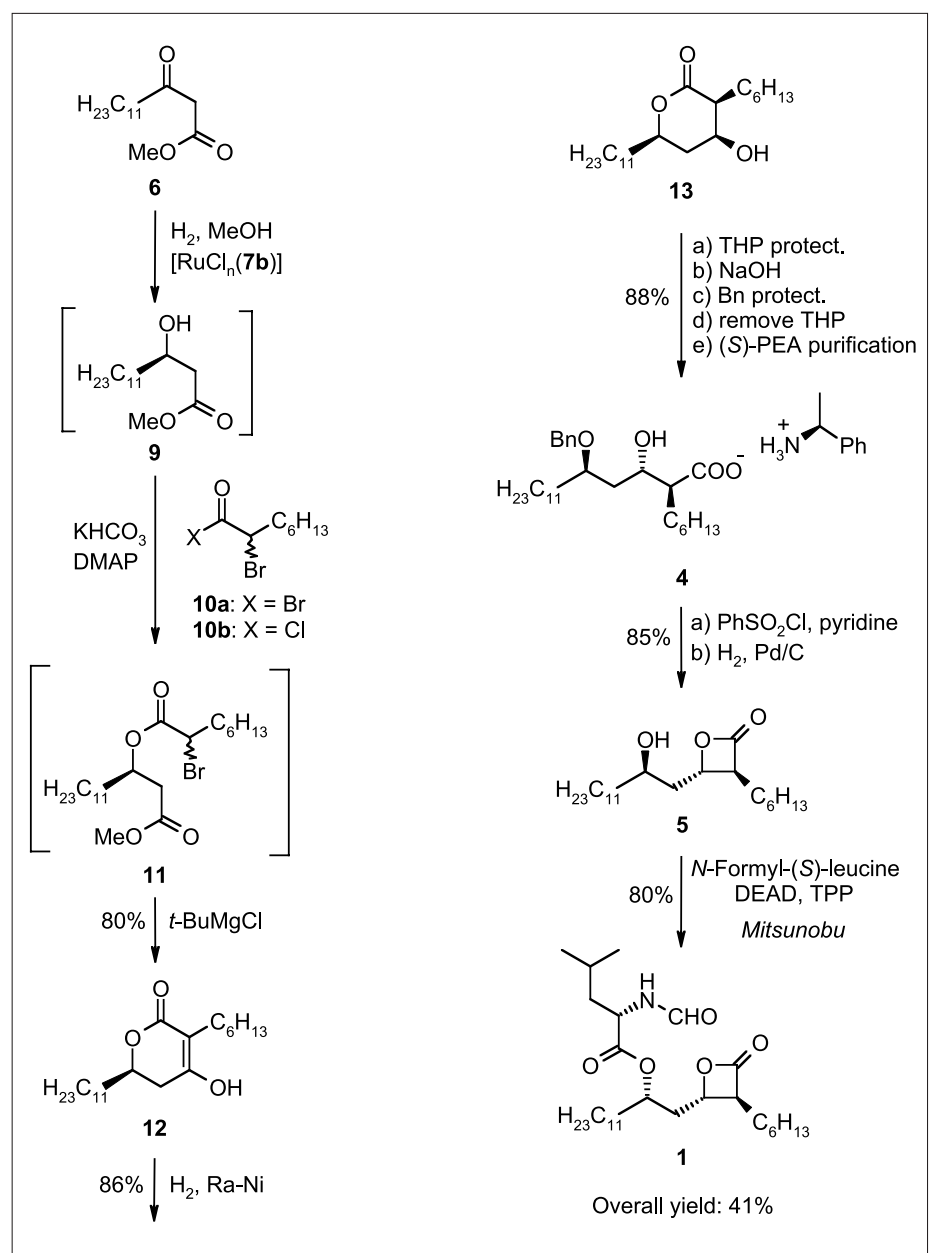

Scheme 2. Second-generation, enantioselective synthesis of Orlistat (1) however, a laborious re-modification with tartaric acid was required after each run to maintain its activity and selectivity. For large-scale production the re-modification procedure was not practicable and a single use of the catalyst proved to be not economically feasible. Furthermore, one crystallization step was still necessary to enhance the ee of $\mathbf{9}$ to $>99 \%$. Therefore this process was not further developed. The promising results obtained with the ruthenium-catalyzed asymmetric hydrogenation of $\mathbf{6}$ (see above) encouraged us to focus on this approach with the goal to elaborate a technically feasible, highly enantioselective (>99\% ee) hydrogenation process which affords enantiomerically pure $\mathbf{9}$ and avoids an ee-enhancing crystallization step. The ready availability of the chiral diphosphine ligand on a multi-kg scale and a robust, scalable catalyst synthesis were additional prerequisites of the targeted new enantioselective hydrogenation process.

\section{Results and Discussion}

\subsection{Enantioselective Synthesis of (R)-Dihydropyrone}

The first reaction sequence in the new, enantioselective synthesis of $\mathbf{1}$ consists of three distinct chemical reactions: i) the asymmetric hydrogenation of $\mathbf{6}$ to $(R)$-hydroxyester $\mathbf{9}$; ii) the acylation of $\mathbf{9}$ to the $(R)$-bromodiester $\mathbf{1 1}$ and iii) the cyclization of $\mathbf{1 1}$ to $(R)$-dihydropyranone $\mathbf{1 2}$ with only 12 being isolated as a solid intermediate.

\subsubsection{The Asymmetric Hydrogenation of 6}

The substrate for the asymmetric hydrogenation, the $\beta$-ketoester $\mathbf{6}$, became commercially available during the course of our investigations but was first prepared in-house on a multi-100 kg scale by condensation of lauroyl chloride with the magnesium salt of methyl acetoacetate in up to $87 \%$ yield [3e][5][11].

The pre-catalysts $\mathbf{8 a}-\mathbf{m}$ for the asymmetric hydrogenation of $\mathbf{6}$ were prepared by reaction of the enantiomerically pure diphosphines (structures in Scheme 3) with commercially available $\left[\mathrm{RuCl}_{2}(\mathrm{COD})\right]_{\mathrm{n}}$ (exemplified by $\mathbf{8 b}$, Scheme 4) [10][12]. As expected, the diacetoxy complex $\mathbf{8 b}$ was catalytically inactive (Table 1 , entry 1 ), but addition of hydrogen chloride generated a catalytically active species [8b-c][13]. Although only 2 molar equiv. of hydrogen chloride are formally required to exchange the two coordinated acetates in $\mathbf{8 b}$ and to form the proposed dichloro catalyst
(Scheme 4) [14], the addition of up to a 20fold excess was extremely advantageous leading to highly increased reaction rates and higher enantioselectivities. Therefore, we suggest that the catalytic species can be written as $\left[\mathrm{RuCl}_{\mathrm{n}}((R)-\mathrm{MeOBIPHEP})\right]$, not excluding the presence of dimeric species [15]. Suitable chloride sources were both aqueous and anhydrous hydrogen chloride. Interestingly, lithium chloride led to a very active catalyst, whereas other additives such as $\mathrm{HBr}, \mathrm{Bu}_{4} \mathrm{NI}, \mathrm{HBF}_{4}$ or $p$-toluenesulfonic acid were much less effective.

The influence of a variety of chiral diphosphines on the hydrogenation rate and enantioselectivity in the catalysts of type $\left[\mathrm{Ru}(\mathrm{OAc})_{2}\right.$ (diphosphine) $] / 20 \mathrm{HCl}_{\mathrm{aq}}$ was investigated (Table 2). Very high enantioselectivities of $>99 \%$ were achieved only by applying atropisomeric diphosphines such as $(R)$-BIPHEMP 7a, $(R)$-MeOBIPHEP 7b, $(R)$-3,5-tBu-MeOBIPHEP 7c and $(R)$-2Furyl-MeOBIPHEP 7h [16]. The most active catalyst $(98 \%$ conversion within $1 \mathrm{~h}$ at a substrate-to-catalyst ratio (S/C) of 50'000) contained the very sterically demanding $(R)$-3,5-tPe-MeOBIPHEP 7d as the chiral diphosphine ligand. However, with this catalyst the ee of 9 dropped to $94 \%$. Due to the large-scale accessibility of the parent diphosphine $(R)$-MeOBIPHEP, $8 \mathbf{b}$ was se- 


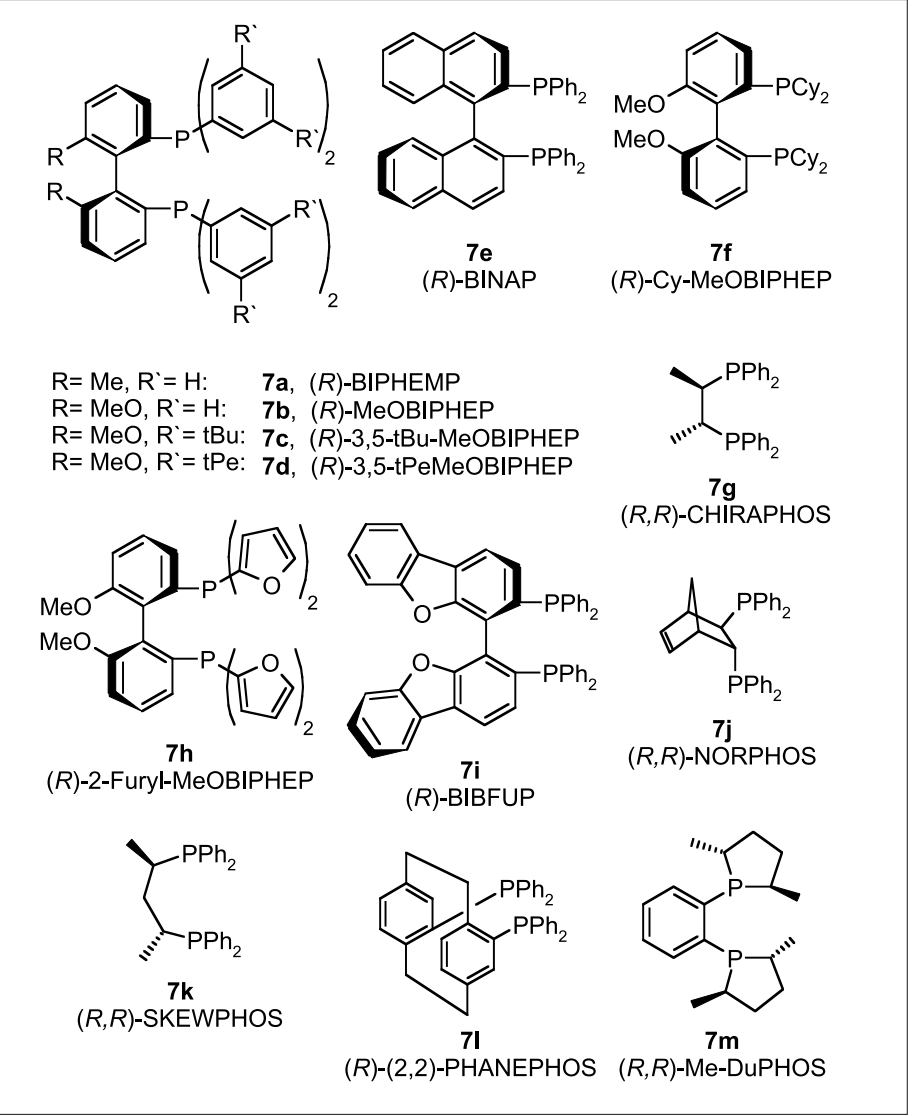

Scheme 3. Structure of various chiral diphosphine ligands
Table 1. Influence of additive and additive/Ru molar ratio ${ }^{\mathrm{a}}$

\begin{tabular}{|c|c|c|c|c|c|}
\hline \multirow[t]{2}{*}{ entry } & \multirow[t]{2}{*}{ additive } & \multirow{2}{*}{$\begin{array}{l}\text { equiv. of } \\
\text { additive }\end{array}$} & \multicolumn{2}{|c|}{ conversion [\%] } & \multirow{2}{*}{$\begin{array}{c}9 \\
\text { ee [\%] }\end{array}$} \\
\hline & & & $1 \mathrm{~h}$ & $4 \mathrm{~h}$ & \\
\hline 1 & - & - & $<1$ & $<1$ & n.d. \\
\hline 2 & $\mathrm{HCl}^{\mathrm{b}}$ & 2 & 4 & 13 & $36^{c}$ \\
\hline 3 & $\mathrm{HCl}^{\mathrm{b}}$ & 4 & 12 & 35 & 26 \\
\hline 4 & $\mathrm{HCl}^{\mathrm{b}}$ & 10 & 72 & 99.9 & 96 \\
\hline 5 & $\mathrm{HCl}^{\mathrm{b}}$ & 20 & 90 & $>99.9$ & 99 \\
\hline 6 & $\mathrm{HCl}_{\mathrm{aq}}$ & 20 & 90 & $>99.9$ & 99 \\
\hline 7 & $\mathrm{LiCl}$ & 20 & 87 & 99.9 & 97 \\
\hline 8 & $\mathrm{HBr}_{\mathrm{aq}}$ & 20 & 31 & 78 & 46 \\
\hline 9 & $\mathrm{HBF}_{4}$ & 20 & 1 & 15 & $33^{c}$ \\
\hline 10 & $p-\mathrm{TsOH}$ & 20 & 50 & 96 & 62 \\
\hline 11 & $\mathrm{Bu}_{4} \mathrm{NI}$ & 20 & $<1$ & $<1$ & n.d. \\
\hline $\begin{array}{l}\text { ab/ad } \\
{ }^{b} \text { Anhyd } \\
{ }^{c}(S)-9\end{array}$ & $\begin{array}{l}\text { S/C 50'0 } \\
\text { methanol }\end{array}$ & $\begin{array}{l}\text { bar } \mathrm{H}_{2}, 8 \\
\text { (prepare }\end{array}$ & hec & $\begin{array}{l}\text { wt.-\%); } \\
\text { f AcCl }\end{array}$ & $\begin{array}{l}\text { g scale. } \\
\text { MeOH). }\end{array}$ \\
\hline
\end{tabular}

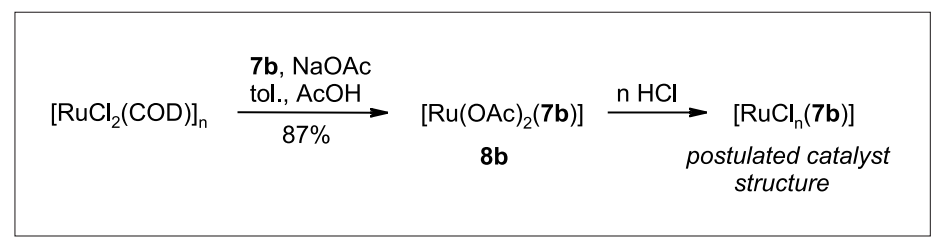

Scheme 4. Synthesis of the hydrogenation catalyst

lected as the pre-catalyst for the asymmetric hydrogenation of $\mathbf{6}$. The intermediate $\mathbf{8 b}$ proved to be remarkably air stable. Storage of $\mathbf{8 b}$ on the bench at room temperature for six months caused no decrease in catalytic activity nor enantioselectivity at S/C 50 '000 compared with freshly prepared $\mathbf{8 b}$ or a sample of $\mathbf{8 b}$, which had been stored at room temperature under an argon atmosphere for six months. The ${ }^{31} \mathrm{P}$ NMR spectra of air-exposed $\mathbf{8 b}$ showed the formation of a small amount of the bis-oxide of $\mathbf{7 b}$ (bisoxide of $\mathbf{7 b} / \mathbf{8 b} \sim 1: 10)$. Evidently, this impurity had no influence on the formation of the catalytically active species. In contrast, the catalyst formed in solution by treatment of $\mathbf{8 b}$ with $\mathrm{HCl}$ in methanol was highly air sensitive: stirring this catalyst solution for $10 \mathrm{~min}$ in air caused a total loss of activity. Therefore, total exclusion of air during both the catalyst formation step and the hydrogenation was crucial for high catalyst performance. Notwithstanding, complete conversion and 99\% ee were achieved with an S/C ratio as high as $250^{\prime} 000$ (Table 3 ), no matter if high purity [17] or technical grade gases [18] and solvents were used, thus indicating the commercial potential and the robustness of the asymmetric hydrogenation step. Finally, in order to achieve a high throughput on a commercial scale, a S/C ratio of 50 '000 at 40 bar hydrogen pressure, which led to complete conversion within $c a .4 \mathrm{~h}$, was selected for scale-up. The hydrogenation also proceeded selectively at a lower hydrogen pressure (e.g. 5 bar), but a fivefold amount of $\mathbf{8 b}$, i.e. S/C $10^{\prime} 000$ had to be employed to achieve complete conversion. In contrast, at a hydrogen pressure of 70 bar the hydrogenation rate increased, but the enantioselectivity slightly decreased (Table 4). Surprisingly, a substrate concentration of 40-60 wt \% was necessary for both a high rate and a high enantioselectivity (Table 5). Even at a concentration of $96 \mathrm{wt} \%$, the hydrogenation reached $99 \%$ conversion within $16 \mathrm{~h}\left(\mathrm{~S} / \mathrm{C} 50^{\prime} 000\right)$ and yielded 9 with $97 \%$ ee. On large scale, the hydrogenation was carried out preferentially at concentrations between $40-60 \mathrm{wt} \%$. As expected, a further increase of the reaction temperature brought about an increase of the rate but also a decrease of the enantioselectivity. Finally, a process temperature of $80^{\circ} \mathrm{C}$ was selected. Various qualities of $\mathbf{6}$ delivered either as crystallized material, a methanolic solution or a melt were well suitable for hydrogenation. The final hydrogenation conditions are the following:

catalyst:

$\left[\mathrm{Ru}(\mathrm{OAc})_{2}((R)-\right.$ $\mathrm{MeOBIPHEP})] / \mathrm{HCl}_{\mathrm{aq}}$ $(1: 20)$

$\mathrm{S} / \mathrm{C}$ :

$\mathrm{H}_{2}$ pressure: $\quad 40 \mathrm{bar}$

solvent: methanol

concentration: $40 \mathrm{wt} \%$

temperature: $\quad 80^{\circ} \mathrm{C}$

Using these conditions, the hydrogenation of $200 \mathrm{~g} 6$ (2-1 autoclave) ran to completion within $4 \mathrm{~h}$, affording 9 with $>99 \%$ purity and $>99 \%$ ee. A total of 2.2 tons of 9 in up to $240 \mathrm{~kg}$ batches have been produced accordingly. Thereto, a 2- $\mathrm{m}^{3}$ autoclave was charged with a methanolic solution of 6 and the pre-catalyst $\mathbf{8 b}$ (S/C 50'000). After the autoclave was purged with technical grade nitrogen, $1 \mathrm{~N} \mathrm{HCl}$ (20 equiv. relative to $8 \mathbf{b}$ ) in methanol was added through a 3-1 autoclave-addition-device previously purged with technical grade nitrogen to form the air-sensitive catalyst. Nitrogen was replaced by technical grade hydrogen (40 bar) and 
the temperature set to $40{ }^{\circ} \mathrm{C}$. After $4-16 \mathrm{~h}$ the conversion was complete and the methanolic solution of 9 was used directly in the next step. All batches met set specifications (>99.9\% conversion, $>99 \%$ ee).

\subsubsection{Acylation of $\mathbf{9}$}

The subsequent reaction of $(R)$-hydroxyester 9 with commercially available 2-bromooctanoyl halide $\mathbf{1 0}$ in toluene under modified Schotten-Baumann conditions [19] employing a mixture of 5-mol \% DMAP and 1.5 equiv. of $\mathrm{KHCO}_{3}$ as base provided on a multi-100 $\mathrm{kg}$ scale a $95 \%$ yield of $(R)$-bromodiester 11 which was used as is in the next step.

\subsubsection{Cyclization of $\mathbf{1 1}$}

As an extension of an earlier approach reported by Roche Nutley, who described a Reformatsky reaction in $70 \%$ yield [3f][20], the initial approach was to carry out the ring closure by treatment of a solution of $(R)$-bromodiester 11 in tetrahydrofuran with magnesium metal in $40-50 \%$ yield. The yield was significantly increased by direct activation of $\mathbf{1 1}$ by tert-butyl magnesium chloride [21]. Under the developed conditions, i.e. simultaneous addition of 3.5 equiv. of tert-butyl magnesium chloride and a solution of $\mathbf{1 1}$ in tetrahydrofuran to a small amount of tetrahydrofuran at $60{ }^{\circ} \mathrm{C}, \mathbf{1 2}$ was syn-

Table 2. Influence of diphosphine ligand ${ }^{\mathrm{a}}$

\begin{tabular}{|c|c|c|c|c|c|}
\hline \multirow[t]{2}{*}{ entry } & \multirow[t]{2}{*}{ diphosphine } & \multicolumn{3}{|c|}{ conversion [\%] } & \multirow{2}{*}{$\begin{array}{c}9 \\
\text { ee }[\%]\end{array}$} \\
\hline & & $1 h^{c}$ & $4 \mathrm{~h}$ & $16 \mathrm{~h}$ & \\
\hline 1 & $7 a$ & 45 & $>99.9$ & & 99 \\
\hline 2 & $7 b$ & 26 & 94 & $>99.9$ & 99 \\
\hline 3 & $7 c$ & 66 & $>99.9$ & & 99 \\
\hline 4 & $7 d$ & 98 & $>99.9$ & & 94 \\
\hline 5 & $7 e$ & 32 & 99.7 & $>99.9$ & 96 \\
\hline 6 & $7 f$ & 1 & 2 & 4 & n.d. \\
\hline $7^{b}$ & $7 g$ & $<1$ & $<1$ & 1 & n.d. \\
\hline 8 & $7 \mathrm{~h}$ & 1 & 5 & 20 & 99 \\
\hline 9 & $7 i$ & 8 & 45 & 99.9 & 97 \\
\hline $10^{b}$ & $7 \mathrm{j}$ & 7 & 34 & 91 & 64 \\
\hline 11 & $7 k$ & 2 & 10 & 60 & 72 \\
\hline 12 & 71 & 9 & 13 & 22 & 39 \\
\hline $13^{c}$ & $7 m$ & $<1$ & $<1$ & $<1$ & n.d. \\
\hline $14^{d}$ & $7 b$ & 56 & 99.9. & $>99.9$ & 96 \\
\hline
\end{tabular}

${ }^{a}\left[\mathrm{Ru}(\mathrm{OAc})_{2}\right.$ (diphosphine) $] / 20 \mathrm{HCl}_{\mathrm{aq}}, \mathrm{S} / \mathrm{C} 50$ '000, 70 bar $\mathrm{H}_{2}, 60^{\circ} \mathrm{C}, \mathrm{MeOH}$ (30 wt.-\%); $15 \mathrm{~g}$ scale; b S/C 5'000. c [RuCl(p-cymene) $(7 \mathrm{~m})] \mathrm{Cl} / 18 \mathrm{HCl}_{\mathrm{aq}}$ used as catalyst (S/C 5'000). d $\left[\mathrm{RuCl}\left(p\right.\right.$-cymene)(7b)]Cl/18 $\mathrm{HCl}_{\mathrm{aq}}$ used as catalyst (S/C 50'000). ' In various instances we observed incubation times which in some cases were also not reproducible (probably due to different substrate and catalyst qualities). Since also most experiments were carried out only once, the conversion especially the one given after $1 \mathrm{~h}$ has to be interpreted cautiously.

Table 3. Influence of $\mathrm{S} / \mathrm{C}^{\mathrm{a}}$

\begin{tabular}{|c|c|c|c|}
\hline entry & $\mathrm{S} / \mathrm{C}$ & $\begin{array}{c}\text { time }[\mathrm{h}] \text { for } \\
>99.9 \% \text { conv. }\end{array}$ & [\%] ee \\
\hline 1 & $50 ` 000$ & 4 & 99 \\
\hline 2 & $100 ‘ 000$ & 6 & 99 \\
\hline 3 & $250 ‘ 000$ & 22 & 99 \\
\hline 4 & 1‘000‘000 & $>36$ & 91 \\
\hline
\end{tabular}

thesized on a multi-100 kg scale in $84 \%$ yield.

\subsection{Synthesis of $(3 S, 4 S, 6 R)-\delta$ - Lactone 13}

In the second reaction sequence, no major changes from the first-generation process were needed to diastereoselectively reduce enantiomerically pure $\mathbf{1 2}$ to enantiomerically pure $\mathbf{1 3}$. Raney Nickel catalyzed heterogeneous hydrogenation of 12 afforded $\mathbf{1 3}$ on a multi-100 kg scale in $86 \%$ yield.

\subsection{Synthesis of PEA-Salt 4}

The subsequent third reaction sequence was also carried out in analogy to the firstgeneration process. Hydroxy- $\delta$-lactone 13 was first THP-protected, followed by saponification of the $\delta$-lactone, selective benzylation of the $\delta$-hydroxy group and deprotection of the THP-ether. After treatment with $(S)$-phenylethylamine, the enantiomerically pure PEA-salt $\mathbf{4}$ was isolated in double the yield of $\mathbf{4}$ to that produced by the first-generation optical resolution based process. Isolation of $\mathbf{4}$ via crystallization remained necessary to meet the set purity specifications and to ensure a substrate quality suitable for further transformation into $\mathbf{1}$. 4 was produced on a multi-100 kg scale in $88 \%$ yield.

\subsection{Final Steps to Orlistat}

There are virtually no differences in the last reaction sequence between the first- and

Table 4. Influence of hydrogen pressure ${ }^{a}$

\begin{tabular}{cccc} 
entry & $\begin{array}{c}\mathrm{H}_{2} \text { pressure } \\
\text { [bar] }\end{array}$ & $\begin{array}{c}\text { time }[\mathrm{h}] \text { for } \\
>99.9 \% \text { conv. }\end{array}$ & [\%] ee \\
\hline 1 & 5 & $>48$ & 98 \\
2 & 40 & 18 & 97 \\
3 & 70 & 6 & 96 \\
4 & 100 & 4 & 94 \\
\hline $\mathbf{8 b} / 10 \mathrm{HCl}_{\mathrm{aq}}, \mathrm{S} / \mathrm{C} 500^{\prime} 000,80^{\circ} \mathrm{C}, \mathrm{MeOH}(30$ wt.-\%);15 g scale.
\end{tabular}

Table 5. Influence of concentration ${ }^{a}$

\begin{tabular}{|c|c|c|c|}
\hline entry & $\begin{array}{l}\text { concentration } \\
\text { [wt.-\%] }\end{array}$ & $\begin{array}{c}\text { time }[\mathrm{h}] \text { for } \\
>99.9 \% \text { conv. }\end{array}$ & $\%$ ee \\
\hline 1 & 10 & $-b$ & 78 \\
\hline 2 & 40 & 4 & 99 \\
\hline 3 & 60 & 4 & 99 \\
\hline 4 & 80 & 16 & 98 \\
\hline 5 & 96 & $>16$ & 97 \\
\hline
\end{tabular}


second-generation Orlistat processes for the conversion of $\mathbf{4}$ to $\mathbf{1}$. Benzenesulfonyl chloride-promoted $\beta$-lactonization of $\mathbf{4}$ and subsequent debenzylation afforded HBL 5 in $85 \%$ yield (Step 4 ). In the last step (Step $5)$, the N-Formyl-( $S)$-leucine building block was introduced using Mitsunobu conditions to yield Orlistat (1) on a multi-kg scale in $80 \%$ yield. The second-generation process produced 1 that was equivalent and met all first-generation specifications.

\section{Conclusions}

The comparison of first- and secondgeneration Orlistat processes shows significant improvements for the new synthetic route. The overall yield of the enantioselective, second-generation process for $\mathbf{1}$ from 6 amounts to $41 \%$, which compares very favorably with the $18 \%$ achieved with the first-generation, optical resolution-based process. Particularly, the herein described hydrogenation process proved to be highly robust, such that the large-scale production of $\beta$-hydroxyester 9 with very high ee $(>99 \%)$ and purity $(>99 \%)$ by asymmetric hydrogenation of $\beta$-ketoester $\mathbf{6}$ was straightforward and practical.

In summary, the goal set at the beginning of the work, i.e. to create a significantly more efficient process by obviating the late-stage resolution present in the firstgeneration process, was achieved.

\section{Acknowledgements}

The authors thank their colleagues M.P. Fleming, Y. Han, L.M. Hodges, D.A. Johnston, R.P. Micheli, R. Dauer, C.R. Roberts, R. Snyder, R.J. Topping, T. Federaro, I. Nuiry and L. Bryant from Roche Colorado Corporation and M. Häss, D. Spiess, S. Brogly and C. Tournoux from F. Hoffmann-La Roche Ltd Basel. We also wish to thank Rudolf Schmid for helpful discussions and Ralf Hauck and the Supply Center Basel team for the successful demonstration of the asymmetric hydrogenation process on a multi $100-\mathrm{kg}$ scale.

Received: June 17, 2006

[1] a) J.B. Hauptman, ' 8 th International Congress on Obesity', Paris, France, August 1998; b) J. Prous, N. Mealy, J. Castaner, Drugs of the Future 1994, 19, 1003.

[2] a) E.K. Weibel, P. Hadvary, E. Hochuli, E. Kupfer, H. Lengsfeld, J. Antibiot. 1987, 40, 1081; b) E. Hochuli, E. Kupfer, R. Mauer, W. Meister, Y. Mercadal, K. Schmidt, J. Antibiot. 1987, 40, 1086.

[3] a) P. Barbier, F. Schneider, Helv. Chim. Acta 1987, 70, 196; b) J.M. Pons, P. Kocienski, Tetrahedron Lett. 1989, 30, 1833; c) I. Fleming, N.J. Lawrence, Tetrahedron Lett. 1990, 31, 3645; d) N.K. Chadha, A.D. Batcho, P.C. Tang, L.F. Courtney, C.M. Cook, P.M. Wovkulich, M.R. Uskoko- vic, J. Org. Chem. 1991, 56, 4714; e) S.C. Case-Green, S.G. Davies, C.J.R. Hedgecock, Synlett 1991, 11, 781; f) J.J.Jr. Landi, L.M. Garofalo, K. Ramig, Tetrahedron Lett. 1993, 34, 277; g) S. Hanessian, A. Tehim, P. Chen, J. Org. Chem. 1993, 58, 7768; h) A. Pommier, J.M. Pons, Synthesis 1994, (Spec. Issue), 1294; i) B. Giese, M. Roth, J. Braz. Chem. Soc. 1996, 7, 243; j) I. Paterson, V.A. Doughty, Tetrahedron Lett. 1999, 40, 393; k) C. Wedler, B. Costisella, H. Schick, J. Org. Chem. 1999, 64, 5301; 1) O. Dirat, C. Kouklovsky, Y. Langlois, Org. Lett. 1999, 1, 753; m) A.K. Ghosh, C. Liu, Chem. Commun. 1999, 17, 1743; n) P.J. Parsons, J.K. Cowell, Synlett 2000, 1, 107; o) A.K. Ghosh, S. Fidanze, Org. Lett. 2000, 2 , 2405 ; p) T. Honda, K. Endo, S. Ono, Chem. Pharm. Bull. 2000, 48, 1545; q) M. Sato, H. Nakashima, K. Hanada, M. Hayashi, M. Honzumi, T. Taniguchi, K. Ogasawara, Tetrahedron Lett. 2001, 42, 2833; r) J.A. Bodkin, E.J. Humphries, M.D. McLeod, Tetrahedron Lett. 2003, 44, 2869; s) A.N. Thadani, R.A. Batey, Tetrahedron Lett. 2003, 44, 8051; t) J. Polkowska, E. Lukaszewicz, J. Kiegiel, J. Jurczak, Tetrahedron Lett. 2004, 45, 3873; u) M. Karpf, U. Zutter, U.S. Patent 5245056A, 1993, European Patent Application EP 443449 A2, 1991.

[4] P.J. Harrington, L.M. Hodges, K. Püntener, M. Scalone, European Patent Application EP 1127886 A1, 2001, U.S. Patent 6552204 B1, 2000.

[5] a) M.P. Fleming, Y.K. Han, L.M. Hodges, D.A. Johnston, R.P. Micheli, K. Püntener, C.R. Roberts, M. Scalone, M.A. Schwindt, R.J. Topping, U.S. Patent 6858749 B2, 2005; U.S. Patent 6743927 B2, 2004; b) A full report on the magnesium-mediated route to $\mathbf{1 2}$ will be published in $\mathrm{Org}$. Proc Res. \& Dev., 2006.

[6] M. Utaka, H. Higashi, A. Takeda, Chem. Commun. 1987, 1368.

[7] W. Liu, M. Oikawa, K. Fukase, Y. Suda. H. Winarno, S. Mori, M. Hashimoto, S. Kusumoto, Bull. Chem. Soc. Jpn. 1997, 70, 1441.

[8] a) M. Nakahata, M. Imaida, H. Ozaki, T. Harada, A. Tai, Bull. Chem. Soc. Jpn. 1982, 55, 2186; b) R. Schmid, M. Scalone, in 'Comprehensive Asymmetric Catalysis III', Ed. E.N. Jacobsen, A. Pfaltz, H. Yamamoto, 1999, p. 1446; c) R. Schmid, E. Broger, M. Cereghetti, Y. Crameri, J. Foricher, M. Lalonde, R.K. Müller, M. Scalone, G. Schoettel, U. Zutter, Pure \& Appl. Chem. 1996, 68, 131.

[9] S.C. Case-Green, S.G. Davies, G. Stephen, C. Hedgecock, Synlett 1991, 11, 781.

[10] B. Heiser, E. Broger, Y. Crameri, Tetrahedron: Asymmetry 1991, 2, 51.

[11] a) M. Viscontini, N. Merckling, Helv. Chim. Acta 1952, 282, 2280; b) T. Sotoguchi, Y. Yuasa, A. Tachikawa, S. Harada, U.S. Patent 5945559, 1999.

[12] A.S.C. Chan, S. Laneman, Inorg. Chim. Acta 1994, 223, 165.
[13] S.A. King, A.S. Thompson, A.O. King, T.R. Verhoeven, J. Org. Chem. 1992, 57 , 6689.

[14] a) R. Noyori, T. Ohkuma, M. Kitamura, H. Takaya, N. Sayo, H. Kumobayashi, S. Akutagawa, J. Am. Chem. Soc. 1987, 109, 5856; b) R. Noyori, Acta Chem. Scand. 1996, 50,380 .

[15] S.A. King, L. DiMichele, Chem. Industries 1995, 62, 157.

[16] a) R. Schmid, M. Cereghetti, B. Heiser, P. Schönholzer, H.J. Hansen, Helv. Chim. Acta 1988, 71, 897; b) M. Cereghetti, J. Foricher, B. Heiser, R. Schmid, European Patent Application EP 398132, 1990; c) J. Foricher, R. Schmid, World Patent Application WO 9315090, 1993; d) J. Foricher, R. Schmid, European Patent Application EP 0926152, 1998; e) J. Foricher, B. Heiser, R. Schmid, European Patent Application EP 0530335, 1992.

[17] Nitrogen and hydrogen ex. Carbagas 60 ( $\geq 99.99990 \%$ purity)

[18] Nitrogen and hydrogen ex. Carbagas 25 (99.5\% purity).

[19] a) C. Schotten, Ber. 1884, 17, 2544; b) E. Baumann, Ber. 1886, 19, 3218; c) For a review see: N.O.V Sonntag, Chem. Rev. 1953, 52, 237.

[20] a) K.M. Ramig, J.J.Jr. Landi, U.S. Patent 5274143, 1993; b) K.M. Ramig, J.J.Jr. Landi, U.S. Patent 5420305, 1995.

[21] For an entry into the growing area of halogen-magnesium exchange reactions by trans-metallation of Grignard reagents see: a) H. Ren, P. Knochel. Chem Commun. 2006, 726; b) M. Abarbri, J. Thibonnet, L. Berillon, F. Dehmel, M. Rottländer, P. Knochel, J. Org. Chem. 2000, 65, 4618. 